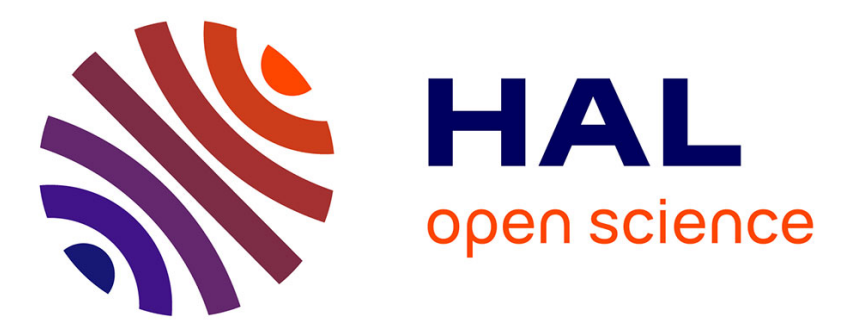

\title{
On the role of particles distribution on damage and fatigue mechanisms
}

Pierre-Olivier Bouchard, Marc Bernacki, Rachid El Khaoulani, Marc Milesi

\section{To cite this version:}

Pierre-Olivier Bouchard, Marc Bernacki, Rachid El Khaoulani, Marc Milesi. On the role of particles distribution on damage and fatigue mechanisms. 12th ESAFORM Conference on Material Forming, Apr 2009, Enschede, Netherlands. pp.Pages 935-938, 10.1007/s12289-009-0615-5 . hal-00509423

\section{HAL Id: hal-00509423}

https://hal-mines-paristech.archives-ouvertes.fr/hal-00509423

Submitted on 12 Aug 2010

HAL is a multi-disciplinary open access archive for the deposit and dissemination of scientific research documents, whether they are published or not. The documents may come from teaching and research institutions in France or abroad, or from public or private research centers.
L'archive ouverte pluridisciplinaire HAL, est destinée au dépôt et à la diffusion de documents scientifiques de niveau recherche, publiés ou non, émanant des établissements d'enseignement et de recherche français ou étrangers, des laboratoires publics ou privés. 


\title{
ON THE ROLE OF PARTICLES DISTRIBUTION ON DAMAGE AND FATIGUE MECHANISMS
}

\author{
Pierre-Olivier Bouchard, Marc Bernacki, Rachid El Khaoulani, Marc Milesi
}

\author{
Mines ParisTech, CEMEF - Centre de Mise en Forme des Matériaux, CNRS UMR 7635, BP 207, 1 \\ rue Claude Daunesse, 06904 Sophia Antipolis Cedex, France
}

\begin{abstract}
Damage and fatigue properties of steel grades are often related to particles shape and chemical composition. To understand the role of particles on damage and fatigue mechanisms numerical modelling at the microscale level can be helpful. It is shown here how forging can induce an oriented microstructure (grain flow orientation) that induces anisotropic damage and fatigue behaviour. Then a microstructure builder (DIGIMICRO) is presented to illustrate how it is possible to create a realistic microstructure in an elementary volume. Computations performed within this heterogeneous elementary volume can be used to understand the anisotropy induced by particles shape and orientation.
\end{abstract}

KEYWORDS: Damage Mechanics - Fatigue - Microstructure - Particles distribution - Finite Element

\section{INTRODUCTION}

Cold forging processes are still widely used in the manufacturing industry to produce parts with complex shapes, at high production rates and with good surface states as well as accurate repetitive tolerances. One of the main consequences of cold forging processes is the creation of a particular microstructure (grain flow orientation) which is known to enhance fatigue properties. Grains and inclusions are elongated in the direction of the process material flaw that has been used to manufacture the product. The work presented here aims at studying the impact of particles distribution on damage and fatigue mechanisms.

On the experimental side, mechanical tests have shown that particles elongation and orientation play a role on damage and fatigue anisotropy. X-Ray tomography insitu tensile tests have been performed to understand the influence of particles orientation on the stages of nucleation, growth and coalescence of microvoids [1].

On the numerical side, a specific microstructure-builder (DIGIMICRO) coupled with a finite element library (CIMLIB) have been developed to model these phenomena at the microstructure scale [2]. An elementary volume accounting for grains and particles is generated. Level-set techniques are used to locate the position of particles/matrix interfaces and generate a particular refined anisotropic mesh at these interfaces [3]. A stochastic methodology can be used to generate different microstructures depending on microstructural observations. Statistics of particles morphology, orientation, number and spacing can be defined on the basis of microstructural observations. Then multiple microstructures can be generated for future computations. Damage and fatigue computation can then be performed on these elementary volumes in order to check the influence of particles distribution (number, morphology, orientation, spacing) on damage or fatigue computations [4].

\section{EXPERIMENTAL OBSERVATIONS}

In a first part, mechanical tests have been performed to show the anisotropy of the studied materials, both in terms of damage mechanisms and fatigue properties.

\subsection{DAMAGE}

A cold forge manganese steel grade is studied here. The cylindrical bar diameter is $70 \mathrm{~mm}$ with a kneading rate equal to 15 . The material has been submitted to an isothermal softening annealing. The structure is bainitic with some ferrite islands. Tensile specimen have been cut at $0^{\circ}$ (longitudinal), $45^{\circ}$ and $90^{\circ}$ (radial) with respect to the grain flow orientation. Tensile tests have shown a strong anisotropy [1]. To understand the role of particles distribution (and orientation) on this anisotropy in-situ tensile tests have been performed using both scanning electron microscopy (SEM) and X-Ray tomography. The tomograph used is the one located on the ID15 beam line at the European Synchrotron Radiation Facility

\footnotetext{
* Pierre-Olivier Bouchard: Mines ParisTech, CEMEF - Centre de Mise en Forme des Matériaux, CNRS UMR 7635, BP 207, 1 rue Claude Daunesse, 06904 Sophia Antipolis Cedex, France, Tel: +33 (0)4-93-67-89-21, pierre-olivier.bouchard@mines-paristech.fr
} 
(ESRF) in Grenoble (France) [5]. The initial state of the sample plus several (six to ten) deformed states at increasing values of the plastic strain were recorded during the loading of the sample. These tests provide load-displacement curves for each configuration: 2D images (transverse or longitudinal views are available) of specimens for each scan of the sample, 3D reconstruction based on the set of $2 \mathrm{D}$ images and quantitative measurements such as number of voids, voids volume fraction etc.

Figure 1 shows the difference between longitudinal (left side of the figure) and radial (right side of the figure) damage mechanisms.

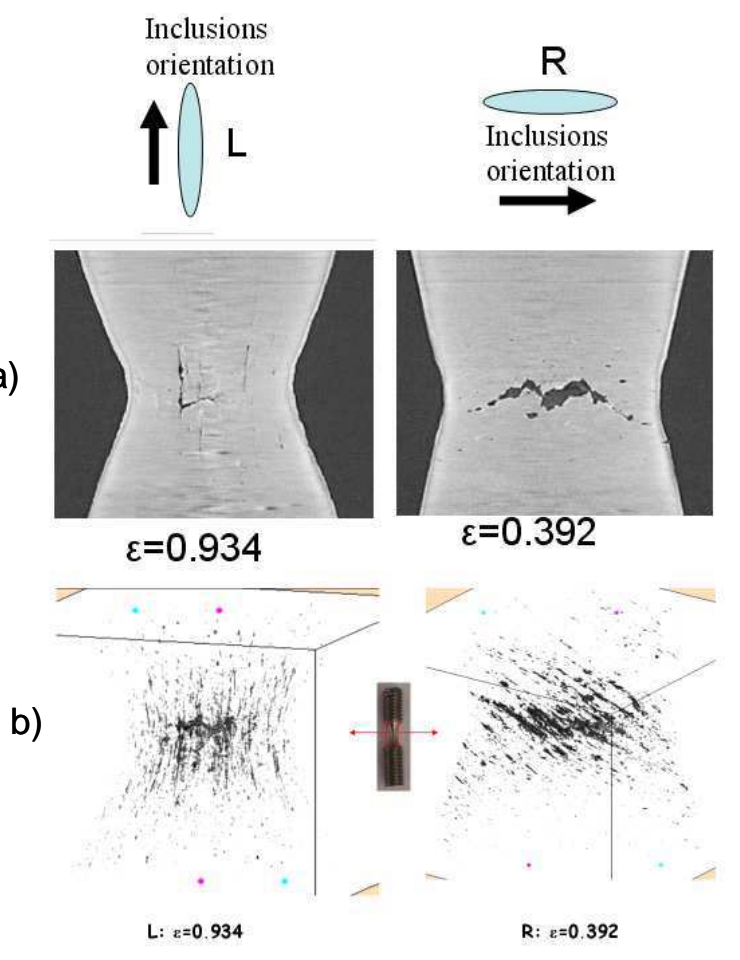

Figure 1: Observations performed during X-Ray in-situ tensile tests. a) $2 D$ view of a cut of the specimen just before fracture and b) $3 D$ reconstruction using Image $J$

\subsection{FATIGUE}

It is well recognized now that cold forging induces a particular microstructure (grain flow orientation) that improves fatigue properties. A bainitic steel, containing Manganese-Sulphide inclusions, has been used (METASCO ${ }^{\circledR}$ ). Tension-compression fatigue tests have been performed on specimen cut at $0^{\circ}, 45^{\circ}$ and $90^{\circ}$ with respect to the grain flow orientation [6]. Table 1 gives the fatigue limit for each direction.
Table 1: Fatigue limits depending on the grain flow orientation

\begin{tabular}{|c|c|c|}
\hline Angle & $\begin{array}{c}\text { Fatigue } \\
\text { limit } \\
\text { (MPa) }\end{array}$ & $\begin{array}{c}\text { Standard } \\
\text { deviation } \\
\text { (MPa) }\end{array}$ \\
\hline $0^{\circ}$ & 476 & 20.5 \\
\hline $45^{\circ}$ & 453 & 8 \\
\hline $90^{\circ}$ & 415 & 11 \\
\hline
\end{tabular}

\section{NUMERICAL MODELING}

Particles orientation is influencing both damage mechanisms and high cycle fatigue properties. To understand the role of particles distribution, a finite element approach is performed at the microstructure level. In the following, only high cycle fatigue applications are presented. First the Papadopoulos fatigue criterion is briefly presented. An anisotropic version of this criterion can be formulated, but it is necessary to identify anisotropic materials parameters. These parameters can be identified using classical fatigue tests on specimen cut in different directions with respect to the grain flow orientation. However such an experimental campaign is long and expensive. A numerical methodology based on microstructure modelling is thus proposed.

\subsection{PAPADOPOULOS FATIGUE CRITERION}

In the Papadopoulos criterion the maximum stress is computed over a complete loading cycle to determine when the structure breaks up (figure 2).

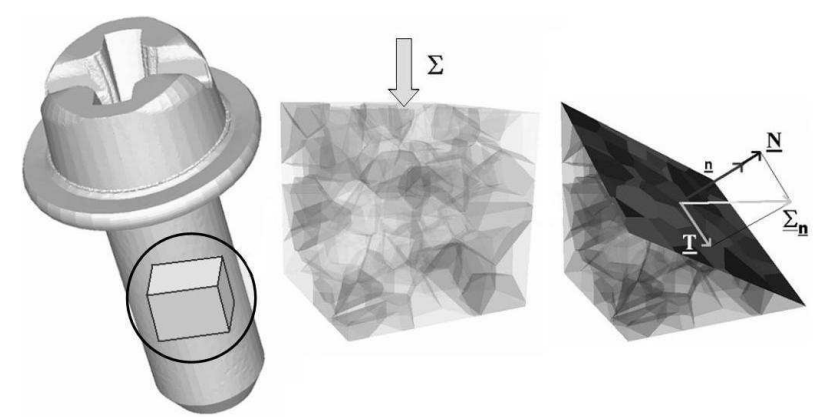

Figure 2: Schematics of a Representative Elementary Volume (R.E.V.)

To calculate this critical stress level for each R.E.V., it is assumed that an adapted state (or shakedown state) with a purely elastic behavior at the grain level, has been reached. Indeed, at the macroscopic level, the structure might be seen as undergoing an elastic loading but, locally, at the microscopic level, it may be possible that one or several grains are unfavourably oriented, thus leading to a local plastic behavior. If no shakedown state can be reached, a crack is initiated at the microscopic 
level; it will lead to a macroscopic crack after some cycles.

Different plane orientations are investigated to determine the maximum value of the shear stress. The secure domain is a linear domain defined by (figure 3):

$$
T_{\Sigma}+\alpha \Sigma_{h, \max } \leq \beta
$$

where $T_{\Sigma}$ is generally obtained by a double maximisation over different plane orientations and over whole cycle. $\Sigma_{h, \max }$ is the maximum hydrostatic stress over the loading cycle [7]. Coefficients $\alpha$ and $\beta$ are deduced from two reference fatigue limits from tension and torsion data.

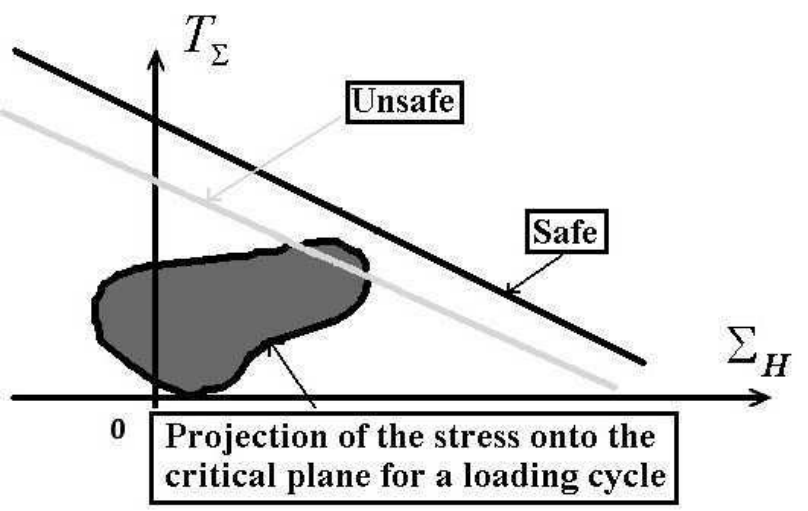

Figure 3: Threshold domain for the Papadopoulos criterion

As shown in table 1, anisotropic fatigue limits are obtained for forged components, depending on the orientation of the test with respect to the grain flow orientation. This would mean that materials parameters $\alpha$ and $\beta$ depend on the orientation of the microstructure. Identifying $\alpha(\underline{n})$ and $\beta(\underline{n})$ (where $\underline{n}$ represents the normal to the critical plane chosen within the Papadopoulos criterion) require fatigue mechanical tests on specimen cut at $0^{\circ}, 45^{\circ}$ and $90^{\circ}$ with respect to grain flow orientation. The objective of the microstructural modelling is to try to identify these parameters based on numerical modelling results at the microscale.

\subsection{MICROSTRUCTURE MODELLING}

\subsubsection{Generation of a virtual microstructure (DIGIMICRO®)}

Microstructural observations have been performed on the METASCO $®$ material. These observations give a certain number of statistics in terms of particles density, orientation, morphology and spacing. Based on this statistics, a microstructure builder, DIGIMICRO ${ }^{\circ}$, enables the creation of a virtual microstructure including a set of elongated particles in an elementary volume (see figure 4).

\subsubsection{Mesh generation (MTC mesher)}

The MTC automatic mesher and remesher is based on mesh topology improvements [8]. It is a powerful mesher for complex 2D/3D geometries that can also deal with anisotropic mesh refinement and parallel calculation. Based on the DIGIMICRO ${ }^{\circledR}$ virtual microstructure, elementary volume meshes are created using MTC. Meshes are particularly refined at inclusions-matrix interfaces using an anisotropic meshing technique (see figure 5), so that configurations generally exceed 10 million elements.
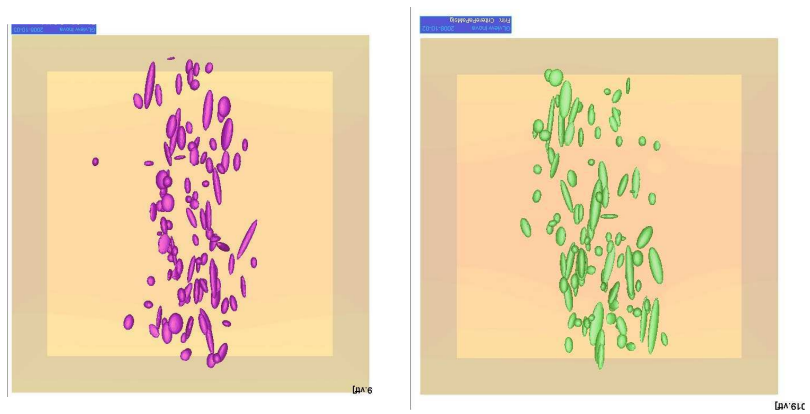

Figure 4: Two different particles distribution generated on the basis of microstructural observations.

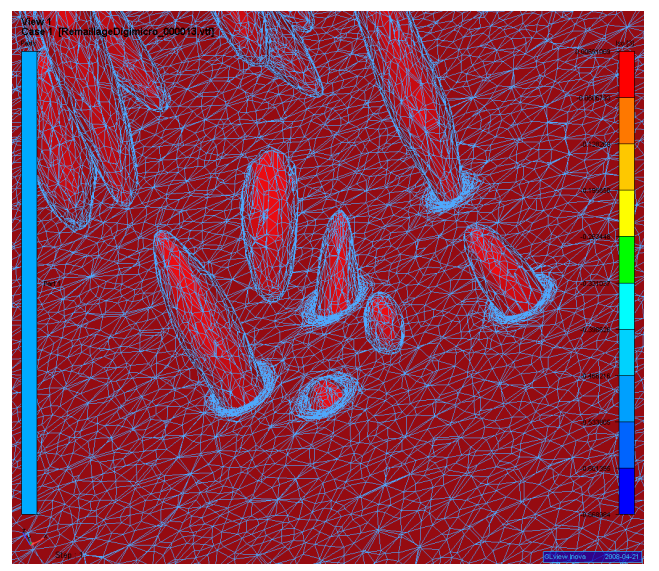

Figure 5: Mesh refinement at inclusions-matrix interfaces

\subsubsection{Mechanical computation (CIMLIB)}

Then, a tension-compression cycle is applied on these elementary volumes for different particles orientation. For a given applied stress, the Papadopoulos criterion is used to determine whether the critical limit is exceeded or not. For each orientation, the fatigue limit can be obtained numerically based on these microstructural simulations. A kill element technique can also be used to model fracture when the criterion has been exceeded (Figure 6). This can be particularly interesting to understand the role of particles distribution in damage mechanics (voids nucleation - growth - coalescence). 


\subsection{RESULTS}

Such computations have been performed for several microstructures generated at $0^{\circ}, 45^{\circ}$ and $90^{\circ}$ with respect to the grain flow orientation. Figure 7 shows the fatigue limits obtained using this methodology. Anisotropic fatigue limits are observed as in the experimental tests: fatigue limits are higher for loadings parallel to the grain flow orientation than for loadings at $45^{\circ}$ or perpendicular to grain flow orientation. However numerical results are more conservatives.

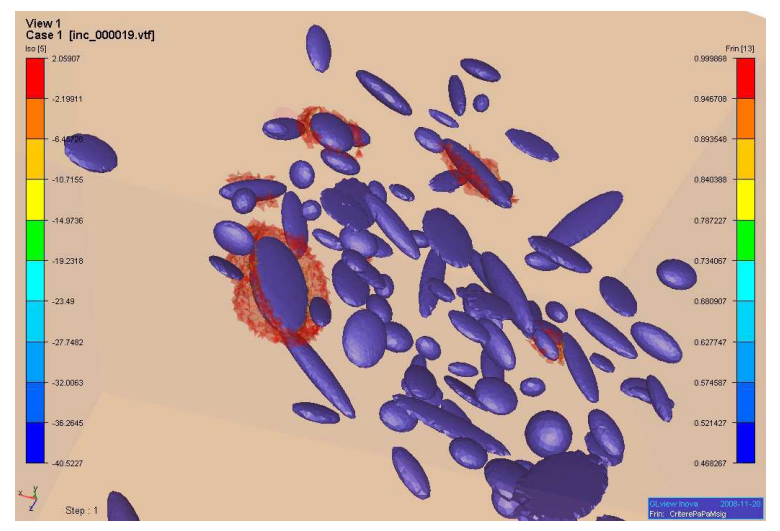

Figure 6: elements exceeding the Papadopoulos limit can be deleted from the mesh to model fracture.

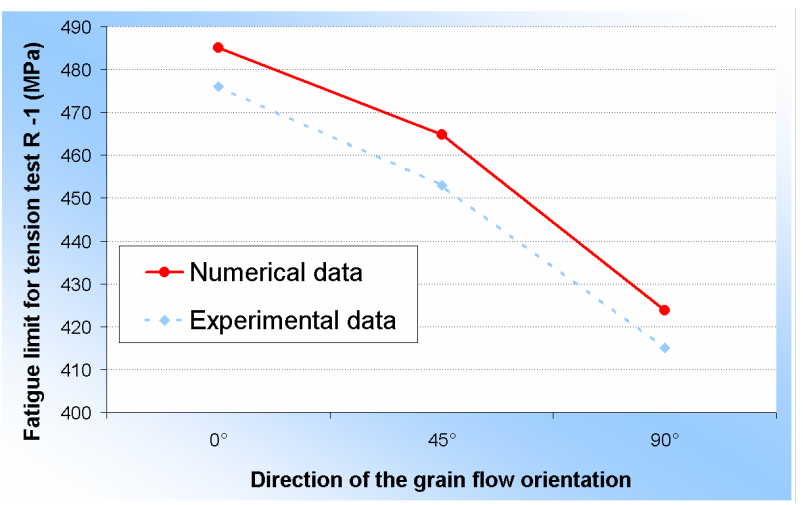

Figure 7: comparison of experimental and numerical anisotropic fatigue limits

\section{CONCLUSIONS}

Particles distribution can give rise to damage and fatigue anisotropy. To study this phenomenon, a microstructural numerical approach has been developed. Based on microstructural observations, DIGIMICRO ${ }^{\circledR}$ enables the generation of 3D elementary volumes including particles. Then, using the CIMLIB mesher (MTC), it is possible to generate accurate meshes of microstructures with a particular anisotropic refinement at particlesmatrix interfaces. Cyclic computations have then been performed on these microstructure. The Papadopoulos fatigue criterion has been used at this scale to determine numerically the materials fatigue limits with respect to the grain flow orientation. Numerical results seem to be in good agreement with experimental ones.

\section{ACKNOWLEDGEMENT}

This work is being performed within the ANR (National Research Agency) Optiforge project, in a partnership including several industrial partners (Ascoforge, Ascometal, Cetim, PSA, Setforge, Transvalor) and academic institutions (ENSAM d'Angers, INSA Lyon, ENSMP - CEMEF).

\section{REFERENCES}

[1] P.O. Bouchard, L. Bourgeon, H. Lachapele, E. Maire, C. Verdu, R. Forestier, R. E. Logé, On the influence of particles distribution and reverse loading on damage mechanisms of ductile steel alloys, Materials Science \& Engineering A, 496: 223-233, 2008.

[2] M. Bernacki Y. Chastel, H. Digonnet, H. Resk, T. Coupez, R.E. Logé, Development of numerical tools for the multiscale modelling of recrystallization in metals, based on a digital material framework, Computer Methods in Materials Science 7: 142-149, 2007.

[3] M. Bernacki, Y. Chastel, T. Coupez, R. E. Logé, Level set framework for the numerical modelling of primary recrystallization in polycrystalline materials, Scripta Materialia 58: 1129-1132, 2008.

[4] M. Milesi, Y. Chastel, M. Bernacki, R. E. Logé, P.O. Bouchard - Explicit microscopic fatigue analysis of forged components, Computer Methods in Materials Sciences, 17(4): 383-388, 2007.

[5] J-Y. Buffière, E. Maire, P. Cloetens, G. Lormand, R. Fougères, Characterization of internal damage in a MMCp using X-ray synchrotron phase contrast microtomography, Acta Mat. 47: 1613-1625, 1999.

[6] E. Pessard, F. Morel, A. Morel, Anisotropic fatigue behaviour in forged Steel, International conference Fatigue and Plasticity from Mechanisms to Design, JIP, Paris, 20-22 May 2008.

[7] F. Morel and L. Flaceliere, Data scatter in multiaxial fatigue: from the infinite to the finite fatigue life regime. Int. J. Fatigue 27: 1089-1101, 2005.

[8] T. Coupez, H. Digonnet, R. Ducloux, Parallel meshing and remeshing by repartitioning, Appl. Math. Modeling 25: 153-175, 2000. 